\title{
Prototipe Sistem Pencatatan Keluar Masuk Barang Menggunakan RFID ISO 18000-6 dan Pembayaran Menggunakan NFC ISO 14443A
}

\author{
Jati Kristianto', Darmawan Utomo², Banu Wirawan Yohanes ${ }^{3}$, Saptadi Nugroho ${ }^{4}$ \\ Program Studi Sistem Komputer, \\ Fakultas Teknik Elektronika dan Komputer, \\ Universitas Kristen Satya Wacana, Salatiga \\ 1622013009@student.uksw.edu, 22 darmawan@staff.uksw.edu , \\ 3banu.yohanes@staff.uksw.edu, ${ }^{4}$ saptadi_nugroho@yahoo.com
}

\begin{abstract}
Ringkasan
Mendata barang pada toko merupakan kegiatan yang cukup melelahkan dan memakan banyak waktu. Selain itu pembayaran pada toko yang masih menggunakan uang kartal juga membutuhkan ketelitian pada saat proses transaksi. Oleh karena itu, dibutuhkan sebuah alat yang dapat memindai barang dengan cara melewatkan barang dan pembayaran tanpa uang kartal. Setiap barang akan dilekatkan Tag RFID yang kemudian akan dibaca oleh RFID reader ketika barang melewati gerbang. Untuk pembayaran menggunakan Tag NFC yang dilekatkan pada handphone, selanjutnya Tag NFC didekatkan pada alat pembayaran yang memiliki NFC reader. Dari hasil pengujian pencatatan barang berhasil mengambil data dari Tag RFID kemudian memasukkan data berupa ID dari produk, nama produk, kategori, dan penyuplai ke database dengan persentase $100 \%$. Untuk sistem pembayaran dapat berhasil mengambil rekaman pada Tag NFC kemudian memasukkan rekaman ke database dan mencetak hasil transaksi dengan persentase $100 \%$. Sistem pencatatan barang berhasil membaca ID dan isi dari Tag RFID, kemudian data tersebut disimpan pada database untuk selanjutnya dicetak dengan menggunakan printer thermal.
\end{abstract}

Kata kunci: RFID, NFC, sistem pencatatan barang, sistem pembayaran

\section{Pendahuluan}

Di beberapa toko masih menggunakan catatan kertas dalam mendata barang yang akan dimasukkan ke gudang toko. Pada saat di toko, karyawan akan memindai barang satu persatu menggunakan barcode. Kemudian karyawan akan menghitung uang dan memberikan pengembalian uang. Ini menyebabkan pembeli menjadi menunggu cukup lama dan karyawan juga membutuhkan tenaga yang ekstra. Terkadang uang yang digunakan juga sudah tidak layak pakai. Bahkan, beberapa toko menggunakan permen sebagai uang kembalian.

Untuk mengatasi masalah tersebut, maka dirancanglah alat yang dapat memindai barang dengan hanya melewatkan barang-barang pada sebuah gerabang. Tag RFID dilekatkan pada setiap barang yang berfungsi sebagai identitas barang. Kemudian Tag tersebut akan dibaca oleh RFID reader yang terdapat pada gerbang. Sedangkan pembayarannya tidak menggunakan uang kartal. Sehingga tidak perlu menghitung uang 
kembalian. Tag NFC ditempelkan pada handphone kemudian Tag tersebut hanya didekatkan pada alat pembayaran.

\section{Perancangan Sistem}

\subsection{Perancangan Pencatatan Barang}

Sistem pencatatan barang memiliki hardware berupa RaspberryPi dan Real Time Clock (RTC) seperti pada Gambar 1. RFID reader akan dihubungkan pada USB to Serial Raspberry Pi. RFID yang digunakan yaitu RFID ISO 18000-6 [1], yang akan berfungsi sebagai pencatatan barang baik pada gerbang gudang, gerbang toko, dan gerbang pembayaran. Kemudian Real Time Clock (RTC) yang dipasang pada pin fisik. RTC tersebut berfungsi sebagai pewaktu yang berfungsi mengetahui kapan barang tersebut berada di gudang, di toko atau sudah terjual.

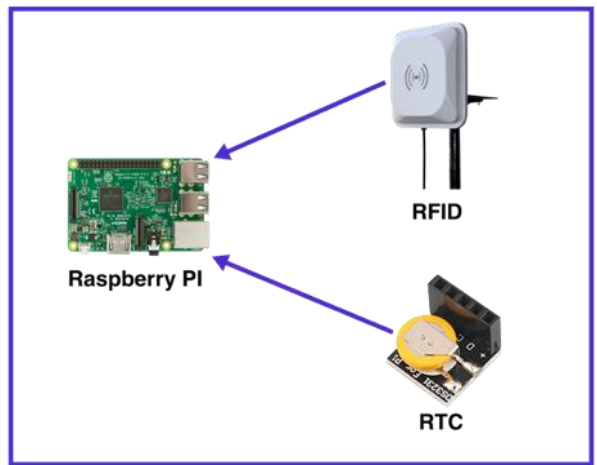

Gambar 1 Desain dan Perangkat Keras Pencatatan Barang

\subsection{Perancangan Pembayaran}

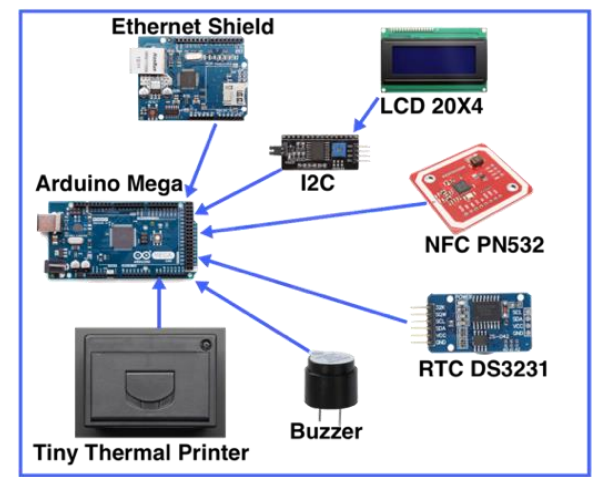

Gambar 2 Desain dan Perangkat Keras Pembayaran

Pembayaran memiliki perangkat keras seperti Arduino Mega, Ethernet Shield, RTC, NFC, Buzzer, dan I2C seperti pada Gambar 2. Ethernet Shield berfungsi untuk menghubungkan ke jaringan. Kemudian NFC berfungsi untuk membaca ID pembeli pada Tag yang dimiliki oleh pembeli. Untuk menghubungkan antara LCD dengan Arduino digunakan I2C yang berfungsi untuk meminimalkan pemasangan kabel. Setelah itu LDC tersebut digunakan sebagai User Interfaces untuk mengetahui transaksi yang dilakukan mengalami kesalahan pada jaringan atau transaksi gagal dilakukan karena tidak ada transaksi. Untuk mengetahui waktu dari sebuah transaksi maka digunakanlah RTC sebagai penghitung waktu transaksi yang dilakukan. Sedangkan Buzzer digunakan 
untuk mengetahui Tag NFC yang didekatkan pada alat pembayaran berfungsi atau tidak, serta dapat atau tidaknya dibaca. Transaksi yang dilakukan oleh pembeli akan dicetak menggunakan Tiny Thermal Printer.

\subsection{Perancangan Server}

Pada sisi server dirancang menggunakan framework Laravel yang berdasarkan pada bahasa pemrograman PHP. Laravel merupakan framework yang berbasis MVC[2]. Pada perancangan ini API yang dibuat hanya menggunakan Model dan Controller. API yang dirancang juga sudah berdasarkan Representional State Transfer Application Programming Interface (REST API) [3]. Gambar 3 merupakan perancangan server, ketika client melakukan request produk menggunakan method GET. Maka controller pada server akan memerintahkan model untuk mengambil semua data produk. Kemudian model akan mengambil data pada database yang selanjutnya data tersebut akan diteruskan kembali ke model. Setelah itu controller akan mendapatkan data dari model untuk diteruskan ke client sebagai response.

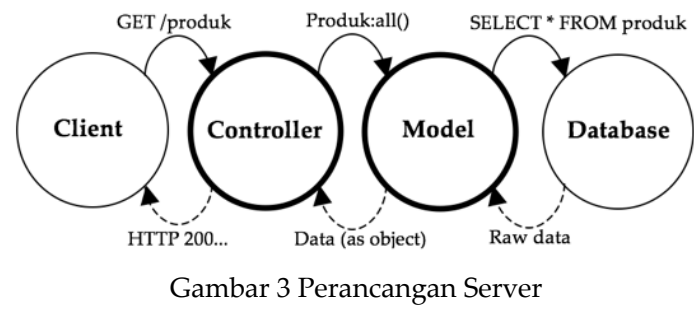

\section{Pengujian}

Untuk melakukan pengujian, Raspberry Pi dan RFID dihubungkan menggunakan USB to Serial. Lalu RTC dihubungkan dengan Raspberry Pi melalui Pin I2C Raspberry Pi. Begitu juga dengan Arduino. NFC, Ethernet Shield, LCD, I2C, dan Thermal Printer dihubungkan dengan Arduino [4][5]. Setelah itu, jalankan server Aplikasi dan server database. Selanjutnya, menghubungkan Raspberry Pi dan Arduino ke jaringan server. Raspberry Pi dihubungkan dengan WLAN sedangkan Arduino menggunakan LAN yang dihubungkan melalui Ethernet Shield.

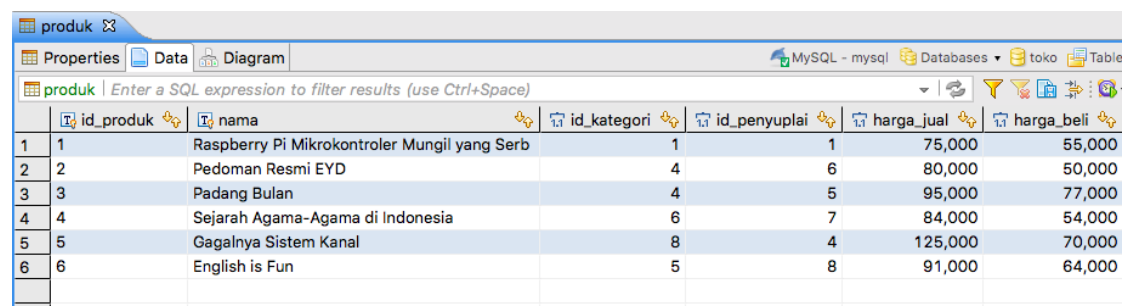

Gambar 4 Hasil Memasukkan Data Produk ke Database

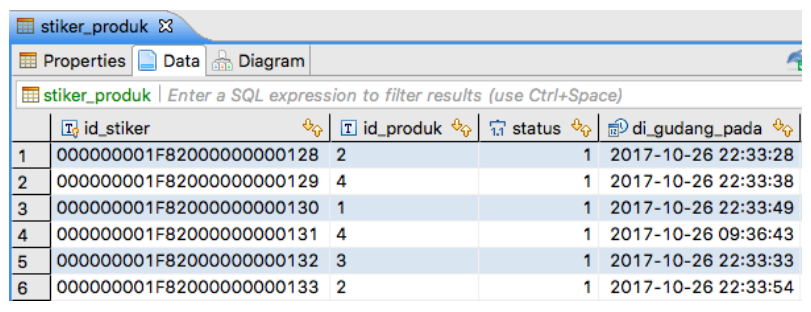

Gambar 5 Hasil Memasukkan Data Stiker ke Database 
Dapat dilihat pada Gambar 4 dan 5 yang mana merupakan hasil dari membaca buku yang dilewatkan secara berurutan satu-persatu pada gerbang gudang. Terdapat status pada stiker yang berisikan "1" pada Gambar 5 yang menandakan bahwa buku tersebut terletak di gudang.

Selanjutnya, buku-buku pada gudang akan dilewatkan pada gerbang toko. Gambar 6 merupakan hasil pencatatan untuk masuk toko yang ditandai dengan perubahan status menjadi " 2 " dan mencatat waktu kapan buku tersebut masuk toko.

\begin{tabular}{|c|c|c|c|c|c|}
\hline \multicolumn{6}{|c|}{ Q stiker_produk $\mathfrak{Z}$} \\
\hline & Properties Data 自 Diagram & & & & MySQL - mysql Databa \\
\hline \multicolumn{6}{|c|}{ 目 stiker_produk | Enter a SQL expression to filter results (use Ctrl+Space) } \\
\hline & $T_{\gamma}$ id_stiker & $\Phi$ id_produk $\Omega_{\widehat{\mathrm{Q}}}$ & 俩苗 status $\Omega_{\mathrm{Q}}$ & 园 di_gudang_pada $\Omega_{\mathrm{Q}}$ & | 圂 di_toko_pada \\
\hline 1 & $000000001 \mathrm{~F} 82000000000128$ & 2 & 2 & $2017-10-26$ 22:33:28 & $2017-10-26$ 22:39:20 \\
\hline 2 & $000000001 F 82000000000129$ & 4 & 2 & $2017-10-2622: 33: 38$ & $2017-10-2622: 39: 20$ \\
\hline 3 & $000000001 \mathrm{~F} 82000000000130$ & 1 & 2 & $2017-10-26$ 22:33:49 & $2017-10-2622: 39: 20$ \\
\hline 4 & $000000001 \mathrm{~F} 82000000000131$ & 4 & 2 & $2017-10-2609: 36: 43$ & $2017-10-26$ 22:39:20 \\
\hline 5 & $000000001 \mathrm{~F} 82000000000132$ & 3 & 2 & $2017-10-26$ 22:33:33 & $2017-10-2622: 39: 20$ \\
\hline 6 & $000000001 \mathrm{~F} 82000000000133$ & 2 & 2 & $2017-10-26$ 22:33:54 & $2017-10-26$ 22:39:20 \\
\hline
\end{tabular}

Gambar 6 Hasil Pencatatan Masuk Toko

Untuk melakukan transaksi, buku-buku yang ada di toko akan dilewatkan pada gerbang pembayaran. Gambar 7 merupakan pencatatan barang yang telah terjual ditandai dengan status yang berubah menjadi " 3 " dan mencatat waktu buku tersebut telah terjual. Sedangkan Gambar 8 merupakan pencatatan transaksi yang dilakukan oleh pembeli.

\begin{tabular}{|c|c|c|c|c|c|c|}
\hline \multicolumn{7}{|c|}{ stiker_produk $\mathbb{Z}$} \\
\hline \multicolumn{2}{|c|}{ 橉 Properties Data Diagram } & \multicolumn{5}{|c|}{ fyySQL - mysql Databases 9 toko Tables . } \\
\hline \multicolumn{6}{|c|}{ W stiker_produk | Enter a SQL expression to filter results (use Ctrl+Space) } & 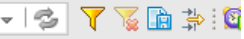 \\
\hline & I id_stiker & T id_produk $\hat{\Omega}_{\mathrm{S}}$ & | & 圂 (di_gudang_pada $\widehat{S}_{\mathrm{S}}$ & |圂 di_toko_pada & 圂 di_jual_pada \\
\hline 1 & $000000001 F 82000000000128$ & 2 & 3 & $2017-10-2622: 33: 28$ & $2017-10-2622: 39: 20$ & $2017-10-2622: 56: 53$ \\
\hline 2 & $000000001 F 82000000000129$ & 4 & 3 & $2017-10-2622: 33: 38$ & $2017-10-2622: 39: 20$ & 2017-11-04 23:10:53 \\
\hline 3 & $000000001 F 82000000000130$ & 1 & 3 & $2017-10-2622: 33: 49$ & $2017-10-2622: 39: 20$ & $2017-10-2622: 56: 53$ \\
\hline 4 & $000000001 F 82000000000131$ & 4 & 3 & $2017-10-2609: 36: 43$ & 2017-10-26 22:39:20 & $2017-10-2622: 56: 53$ \\
\hline 5 & $000000001 F 82000000000132$ & 3 & 3 & $2017-10-2622: 33: 33$ & $2017-10-2622: 39: 20$ & 2017-11-04 23:10:53 \\
\hline 6 & $000000001 F 82000000000133$ & 2 & 3 & $2017-10-2622: 33: 54$ & $2017-10-2622: 39: 20$ & 2017-11-04 23:10:53 \\
\hline
\end{tabular}

\begin{tabular}{|c|c|c|c|c|c|}
\hline \multicolumn{6}{|c|}{ detail_transaksi $\mathfrak{Z}$} \\
\hline \multicolumn{2}{|c|}{ Properties } & Data & gram & & 4 \\
\hline \multicolumn{6}{|c|}{ 国 detail_transaksi | Enter a SQL expression to filter results (use Ctrl+Space) } \\
\hline & 实 id & | & औ & T id_stiker & 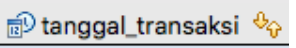 \\
\hline 1 & 1 & & 1 & $000000001 F 82000000000156$ & $2017-10-2622: 56: 53$ \\
\hline 2 & 2 & & 1 & $000000001 F 82000000000140$ & $2017-10-2622: 56: 53$ \\
\hline 3 & 3 & & 1 & $000000001 F 82000000000128$ & $2017-10-2622: 56: 53$ \\
\hline 4 & 4 & & 1 & $000000001 \mathrm{~F} 82000000000130$ & $2017-10-2622: 56: 53$ \\
\hline 5 & 5 & & 1 & $000000001 F 82000000000131$ & $2017-10-2622: 56: 53$ \\
\hline
\end{tabular}

Gambar 8 Hasil Pencatatan Detail Transaksi

Setelah melakukan transaksi selanjutnya dilakukan pengujian pembayaran. Pengujian dapat dilakukan dengan mendekatkan stiker NFC ke alat pembayaran. Gambar 9 merupakan hasil dari pembayaran transaksi yang dilakukan pembeli. Arduino berhasil memasukkan data pembeli ke database dan mencetak bukti transaksi yang dicetak melalui thermal printer. Gambar 10 dan 11 merupakan hasil laporan keuntungan dapat diunduh melalui http://localhost/api/v1/keuntungan?year=2017\&week=44 untuk minggu ke-44 tahun 2017, http://localhost/api/v1/keuntungan?year=2017\&month=11 
untuk bulan November 2017, dan http://localhost/api/v1/keuntungan?year=2017 untuk laporan tahun 2017.
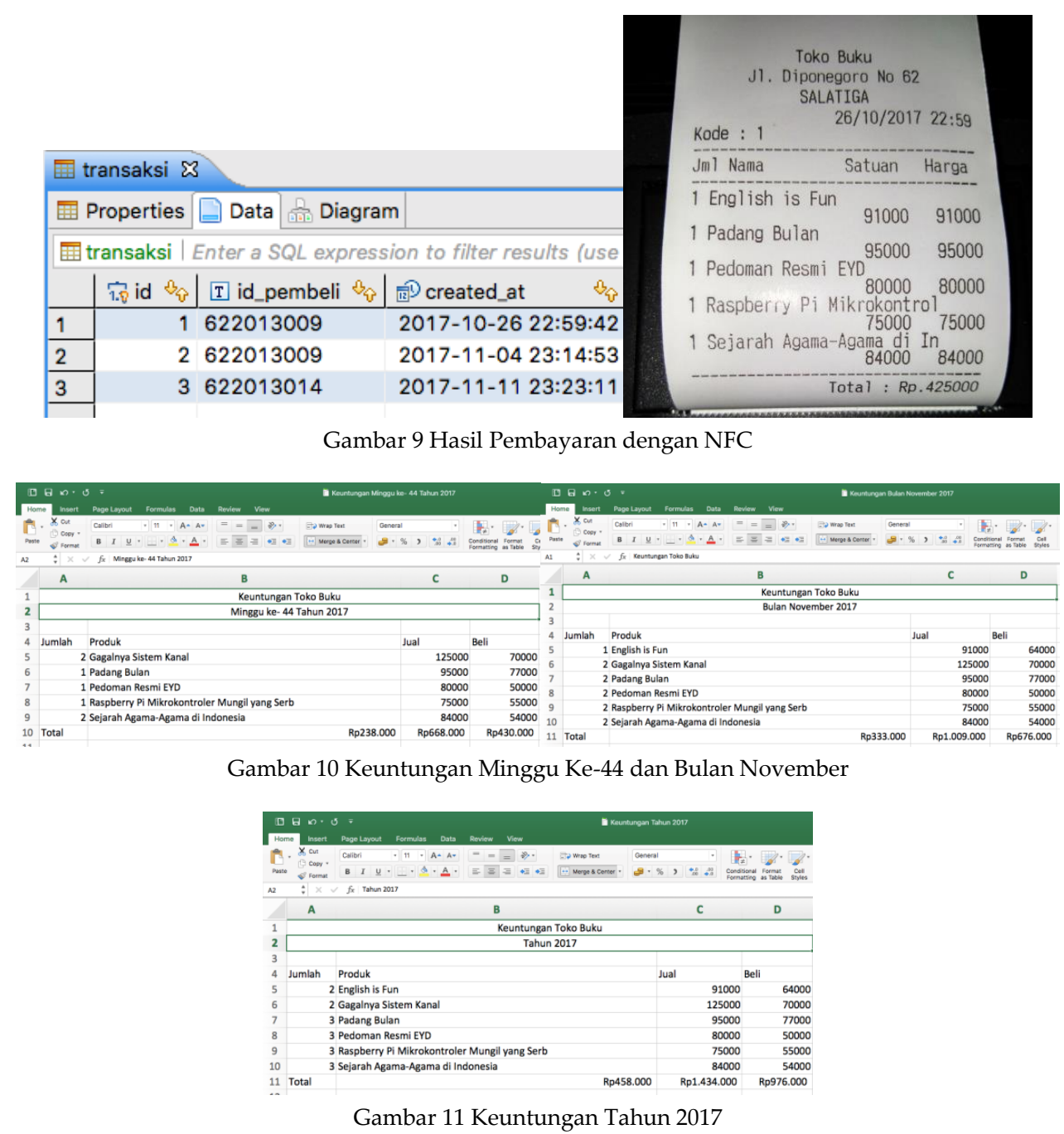

\section{Kesimpulan}

Sistem pencatatan barang berhasil membaca ID dan isi dari Tag RFID, kemudian data tersebut disimpan pada database. Begitu juga dengan sistem pembayaran, dapat membaca rekaman pada Tag NFC. Kemudian rekaman tersebut disimpan pada database. Selanjutnya hasil transaksi yang dilakukan pembeli dapat dicetak dengan menggunakan printer thermal. Untuk hasil keuntungan dapat diunduh dalam bentuk format ".xls". Persentase keberhasilan pengujian sistem secara keseluruhan yaitu $100 \%$.

\section{Daftar Pustaka}

[1] K. Finkenzeller, RFID Handbook, United Kingdom: A John Wileyand Sons, h. 1-23, 2010.

[2] R. Saunier, Getting Started with Laravel 4, United Kingdom: Packt Publishing, h. 14-15, 2014.

[3] M. Massé, REST API Design Rulebook, United States of America: O'Reilly Media, 2012. 
[4] T. Igoe, D. Coleman, and B. Jepson, "Beginning NFC Near Field Communication with Arduino", Android, and Phone Gap, United States of America: O'Reilly Media, 2014.

[5] V. Coskun, K. Ok, B. Ozdenizci, Professional NFC Application Development For Android, United Kingdom: A John Wiley and Sons, 2013. 